Aline Alves França

\title{
Obesidade e a \\ Repercussão na Saúde
}


UNIVERSIDADE DE BRASÍLIA

Centro de Excelência em Turismo

Curso de Especialização em Qualidade em Alimentos

\section{Obesidade e a Repercussão na Saúde}

Projeto de pesquisa submetido ao Curso de Especialização em Qualidade de Alimentos - CET- UnB, como requisito parcial para a obtenção do título de Especialista em Qualidade de Alimentos

\section{Aline Alves França}

Orientadora: Dr ${ }^{\mathrm{a}}$ Anadergh Barbosa de Abreu Branco 


\section{AGRADECIMENTOS}

Em primeiro lugar a Deus, por tudo!!! Aos meus pais pelo amor e incentivo, a professora Anadergh, pelos ensinamentos, aos meus amigos, pela motivação e alegria, e a todos que colaboraram de alguma maneira para a realização deste trabalho. 


\section{Sumário}

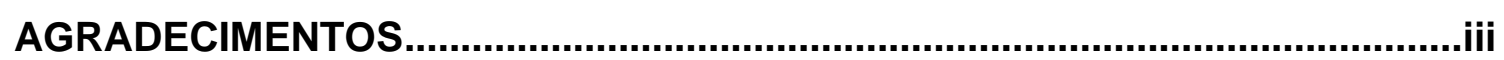

RESUMO

ABSTRACT

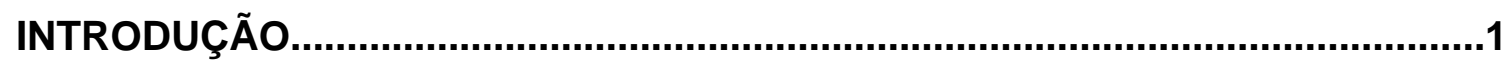

METODOLOGIA

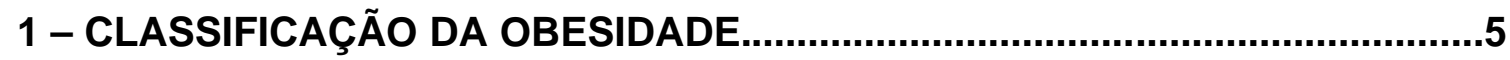

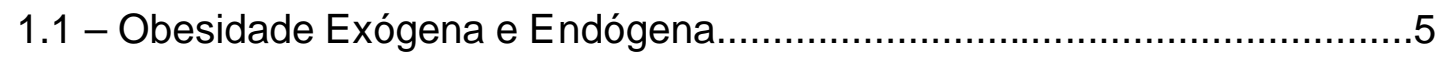

1.2 - Obesidade classificada segundo a quantidade de gordura corporal..........5

1.2.1 - Obesidade Andróide, Ginóide ou Mista.........................................

1.3 - Obesidade Progressiva....................................................................

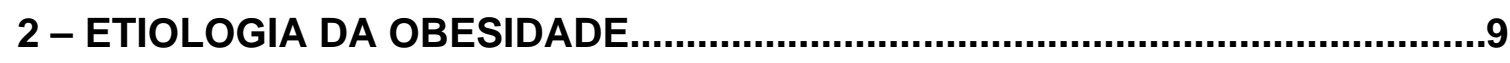

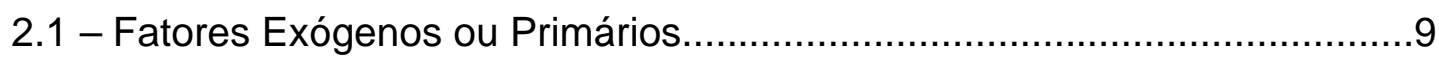

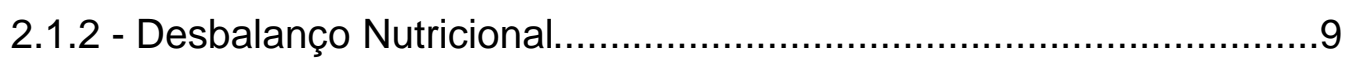

2.1.2 - Inatividade física/sedentarismo..................................................12

2.1.3 - Estresse, depressão e ansiedade..................................................14

2.1.4 - Fatores Socioeconômicos.........................................................14

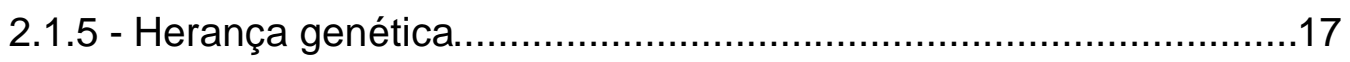

2.1.6 - Hábitos alimentares instalados na infância...................................20

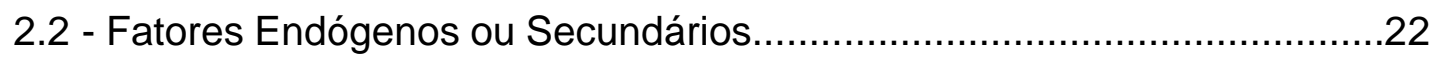

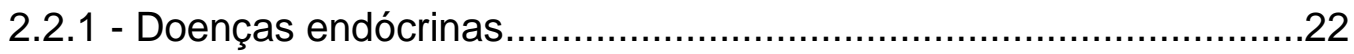

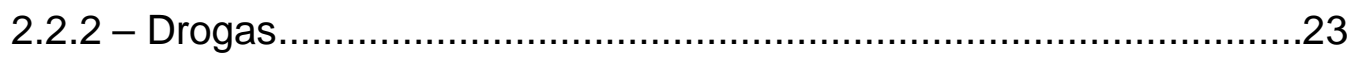

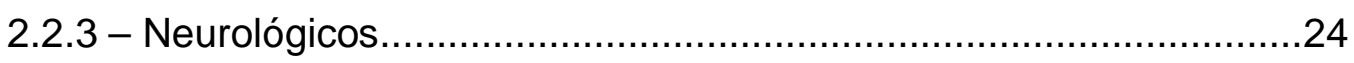

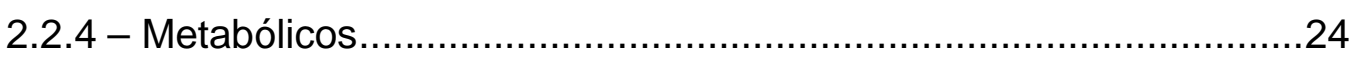

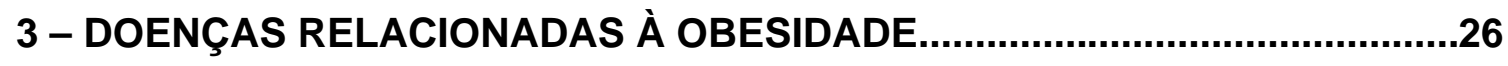

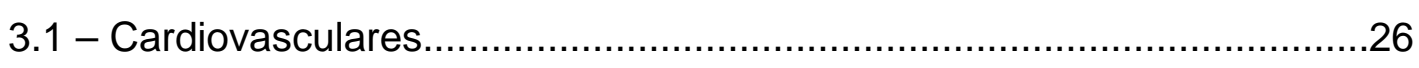

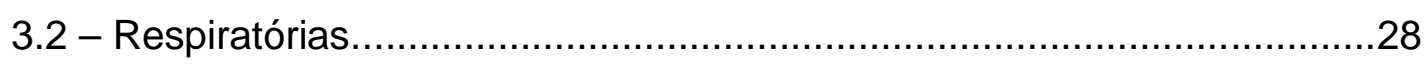

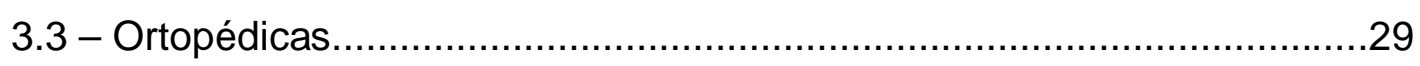

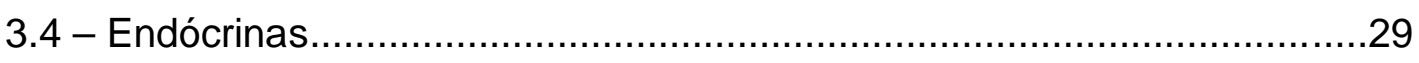

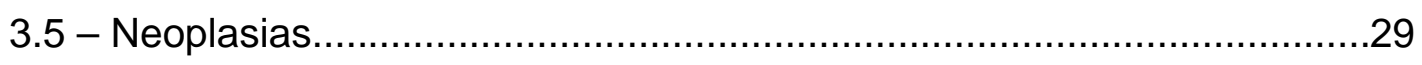




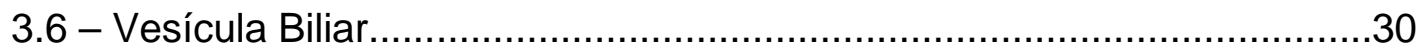

3.7 - Outras Disfunções.............................................................................30

4 - ASPECTOS PSICOLÓGICOS........................................................................31

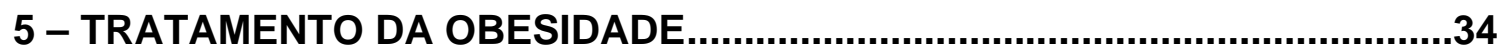

5.1 - Tratamento Dietoterápico........................................................... 34

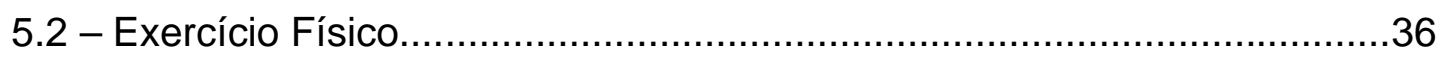

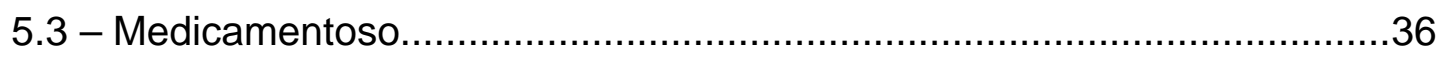

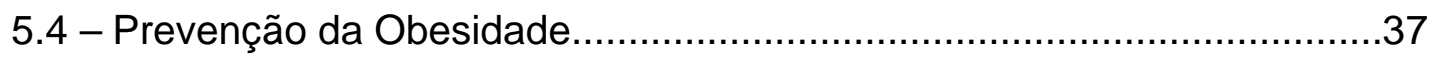

CONCLUSÃO..................................................................................................41

REFERÊNCIAS............................................................................................42

\section{LISTA DE TABELAS}

TABELA 1 - Risco de mortalidade de acordo com a classificação do peso....6 


\section{Resumo}

A obesidade tem se tornado um problema de saúde pública em todo mundo, merecendo maiores estudos da sua relação com outros fatores (comorbidades), bem como de outros fatores com a obesidade.

Foi realizado uma pesquisa bibliográfica nos idiomas português e inglês nos últimos 25 anos; as bases de dados pesquisadas foram a Scielo, Bireme e a base de periódicos da Capes como um todo.

Foram abordados os seguintes tópicos: - classificação da obesidade, etiologia da obesidade, doenças relacionadas à obesidade, aspectos psicológicos e tratamento da obesidade.

A obesidade apresenta apresenta etiologia/associações multifatoriais com distribuição em todas as faixas etárias com predomínio nas faixas mais elevadas e no sexo feminino.

Unitermos: obesidade, efeitos à saúde, saúde pública, morbidade. 


\section{ABSTRACT}

Obesity has become a public health problem all over the world, requiring deeper studies about its relation with other factores (comorbidity), as well as other obesity factores.

A bibliographycal research has been made in Portuguese and English languages in the last 25 years; The databases researched were Scielo, Bireme and Capes Periodical bases, as a whole.

The following topics have been approached: obesity classification, obesity ethiology, sicknesses related to obesity, psychological aspects and therapeutics for obesity.

Obesity presents multifactorial ethiology/associations distributed in all ages, prepondering on the highest ages among female gender.

Uniterms: obesity, effects on health, public health, morbity. 


\section{INTRODUÇÃO}

O "tema" obesidade é considerado relativamente novo. Durante um longo período a humanidade estava mais preocupada com a fome do que com o excesso de ingestão calórica (HALPERN \& MANCINI, 2002), contudo, provavelmente a obesidade é o mais antigo distúrbio metabólico, havendo relatos da ocorrência desta desordem em múmias egípcias e em esculturas gregas (BLUMENKRANTZ, 1997).

No Brasil e no mundo o número de indivíduos com excesso de peso e obesidade é cada vez maior. Diante dos estudos que mostram que a obesidade tornou-se uma epidemia, pode-se afirmar que metade dos pacientes que procuram médicos especialistas apresentam excesso de peso, e a redução desse peso em geral contribui para a melhora do quadro clínico do paciente (HALPERN \& MANCINI, 2002).

De acordo com um recente relatório da Organização Mundial de Saúde (OMS), a obesidade atingiu proporções epidêmicas em todo o mundo, hoje a obesidade é tão comum (aproximadamente 250 milhões de obesos e 500 milhões de pessoas com sobrepeso no mundo) que está começando a substituir a subnutrição e as doenças infecciosas como a doença que mais provoca danos à saúde, podendo causar conseqüências graves (PÉRUSSE, 2002).

A obesidade é uma doença crônica que provoca ou acelera o desenvolvimento de outras doenças como: hipertensão, doença coronariana, diabetes tipo 2, dislipidemias, desencadeia intolerância a glicose, hiperinsulinemia, apnéia do sono, doença da vesícula, osteoartrites, diminuição da fertilidade e 
alguns cânceres (mama, útero, próstata e cólon) levando a uma maior morbimortalidade nos indivíduos. (HALPERN \& MANCINI, 2002).

Em adição, a obesidade e suas complicações têm impacto social e econômico, na área da saúde e da produtividade individual. (HALPERN \& MANCINI, 2002).

A obesidade tem pôr característica um distúrbio do Estado Nutricional traduzido por um aumento do tecido adiposo, reflexo do excesso de gordura resultante do balanço positivo de energia na relação ingestão/gasto calórico (SAITO, 1996). Possui causa multifatorial e mantém-se por diferentes motivos: mau hábito alimentar, predisposição genética e familiar, falsas crenças em torno da gordura, superalimentação, excesso de gorduras e carboidratos na dieta, falta de exercício, estresse, ansiedade, distúrbios emocionais e falta de exercícios que movimentem o corpo no momento do trabalho que levam a um possível sedentarismo (HALPERN \& MANCINI, 2002)

Recentemente a obesidade pôde ser considerada a mais importante desordem nutricional nos países desenvolvidos, tendo em vista o aumento de sua incidência: acredita-se que atinja $10,0 \%$ da população desses países (DYER, 1994) e que mais de um terço da população norte-americana (local onde os alimentos ricos em energia são abundantes e baratos e os estilos de vida do trabalhador cada vez mais sedentários) esteja acima do peso desejável, (BARON, 1995). O aumento de sua incidência está distribuído em quase todas as raças e sexos, e atinge principalmente a população de 25 a 44 anos (BLUMENKRANTZ, 1997).

As tendências internacionais atuais revelam um rápido aumento na prevalência de obesidade nos últimos 10 a 15 anos. Estudos epidemiológicos, 
baseados no IMC, realizados em 7 países (França, Alemanha, Itália, Espanha, Reino Unido, Estados Unidos e Japão) mostraram que mais de um quarto da população tinha sobrepeso (HALPERN \& MANCINI, 2002)

Dados de inquéritos nacionais sobre saúde e nutrição dos Estados Unidos de 1960 e 1994, indicam um aumento progressivo na prevalência de adultos obesos, sendo particularmente notável o aumento observado entre 1976 e 1994: $12,3 \%$ para $19,9 \%$ entre homens, e $16,9 \%$ para $24,9 \%$ entre mulheres. Dados do Instituto Brasileiro de Geografia e Estatística (IBGE), obtidos em dois períodos (1974-5 e 1989) mostram que a proporção de indivíduos com sobrepeso se elevou de $16,7 \%$ para $24,5 \%$ e de indivíduos com obesidade se elevou de $4,7 \%$ para 8,3 \%. (IBGE, 1989)

Políticas e programas de controle da obesidade são realizados periodicamente, temos um caso ocorrido no dia 11 de outubro de 2003, Brasil, realizado em Brasília, no congresso nacional, o 1ํㅗำsio "Obesidade - uma epidemia", Assinada por várias entidades médicas nacionais e internacionais, o assunto aponta o excesso de peso como um problema que afeta a saúde dos brasileiros e os cofres públicos.

No final do simpósio, foi assinada e feita a leitura da Declaração de Brasília, que aponta a obesidade como um problema de saúde pública crescente no Brasil e que sugere a adoção de medidas emergênciais e preventivas para o combate da doença, onde foi criada a campanha "Menos Gordura, Mais Saúde".

Tendo em vista esse rápido aumento na prevalência da obesidade, a gravidade de complicações que a doença pode ocasionar o presente trabalho tem como objetivo apresentar as causas da obesidade e suas complicações na saúde. 


\section{METODOLOGIA}

Foi realizado uma pesquisa bibliográfica nos idiomas português e inglês nos últimos 25 anos; as bases de dados pesquisadas foram a Scielo, Bireme e a base de periódicos da Capes como um todo.

Foram abordados os seguintes tópicos: - classificação da obesidade, etiologia da obesidade, doenças relacionadas à obesidade, aspectos psicológicos e tratamento da obesidade. 


\section{1 - CLASSIFICAÇÃO DA OBESIDADE}

\section{1 - Obesidade Exógena e Endógena}

A obesidade pode ser classificada em exógena e endógena. A exógena reflete excesso de gordura corporal decorrente do equilíbrio energético positivo entre ingestão e demanda energética. Esse tipo de obesidade é responsável por $98 \%$ dos casos. A obesidade endógena tem causas hormonais provenientes de alterações do metabolismo tireoidiano, gonadal, hipotálamo-hipofisiário, de tumores e síndromes (BRAY, 1976), sendo responsável por 2,0\% dos casos.

\section{2 - Obesidade classificada segundo a quantidade de gordura corporal}

Outra forma de classificar a obesidade é de acordo com a quantidade de gordura corporal, que pode ser mensurada por meio do IMC (índice de massa corporal), peso dividido pela altura (em metros) ao quadrado, é o método de avaliação de gordura corporal mais utilizado (HALPERN, 2003), classificado de acordo com a seguinte tabela: 
Tabela 1 - Risco de mortalidade de acordo com a classificação do peso

\begin{tabular}{c|cc}
\hline$I M C\left(\mathrm{~kg} / \mathrm{m}^{2)}\right.$ & Classificação & Risco de co-morbidades \\
\hline$<18,5$ & Baixo peso & Outros problemas clínicos \\
$18,5-24,9$ & Normal & Ausente \\
$25-29,9$ & Pé-obeso & Aumentado \\
$30-34,9$ & Obeso grau I & Moderado \\
$35-39,9$ & Obeso grau II & Grave \\
$=40$ & Obeso grau III & Muito grave \\
\hline
\end{tabular}

FONTE: HALPERN \& MANCINI, 2003

A gordura corporal pode apresentar a seguinte classificação:

1.2.1 - Obesidade Andróide, Ginóide ou Mista

A localização da gordura classifica a obesidade como andróide, ginóide ou mista. A obesidade andróide ou obesidade central, apresenta acúmulo mais acentuado de gordura na região do abdome, tronco, cintura escapular e pescoço (GUEDES \& GUEDES, 2003), sob efeito hormonal da testosterona e de corticóides, manifesta-se sobretudo nos homens A ginóide ou obesidade periférica é caracterizada pelo acúmulo de gordura predominantemente na metade inferior do corpo - regiões do quadril, glúteo e coxa superior (GUEDES \& GUEDES, 2003) sob efeito hormonal dos estrógenos, acumula-se principalmente em mulheres (BRAY, 1976). 
É possível avaliar as características da celularidade do tecido adiposo, considerando o tamanho e o número de células adiposas (HALPERN, 2003), classificada em hipertrófica e hiperplásica:

A hiperplásica está associada ao número acentuado de células adiposas no organismo. Indivíduos com quantidades de gordura dentro dos limites esperados apresentam entre 25 e 30 bilhões de células adiposas, enquanto obesos hiperplásicos podem ter entre 42 e 106 bilhões dessas células. A hipertrófica está associada ao aumento no tamanho das células adiposas existentes. O tamanho das células adiposas de obesos hipertróficos pode alcançar, em média, dimensões $40 \%$ maiores se comparado com os não-obesos (HIRSCH, 1971). A avaliação da celularidade adiposa é realizada por meio de punção/biópsia do tecido subcutâneo para seu estudo histopatológico, esta não é uma técnica de rotina, é utilizada para casos especiais A obesidade mista apresenta aumento difuso do tecido adiposo, sem uma localização particular (HALPERN \& MANCINI, 2002).

\section{3 - Obesidade Progressiva}

A obesidade progressiva se caracteriza pelo aumento gradual da quantidade de gordura desde as idades mais precoses até o estágio adulto. Os períodos críticos de surgimento da obesidade são aos 12 primeiros anos de vida, na fase pré-escolar e na puberdade (BRAY, 1990).

No primeiro ano de vida o número de adipócitos aumenta de 2 a 3 vezes e seu tamanho é de um quarto das células adiposas do adulto. Até os 6 a 7 anos, as células adiposas têm seus tamanhos triplicados, nesta fase é necessário um maior 
controle para não haver um excesso no aumento nessas células. Na adolescência há hiperplasia fisiológica das células adiposas com aumento de sua dimensão. $\mathrm{Na}$ fase adulta, no caso do homem a obesidade se desenvolve após um período mais ativo de vida seguido de sedentarismo, nas mulheres ocorre normalmente após a gestação com grande ganho de peso (HALPERN \& MANCINI, 2003). 


\section{2 - ETIOLOGIA DA OBESIDADE}

A obesidade não é uma desordem singular, e sim um grupo heterogêneo de condições com múltiplas causas que em última análise resultam no fenótipo da obesidade. Os princípios mendelianos e a influência do genótipo na etiologia desta desordem podem ser atenuados ou exacerbados por fatores não-genéticos, como o ambiente externo e interações psicossociais que atuam sobre mediadores fisiológicos de gasto e consumo energético. Provavelmente a etiologia da obesidade é uma das mais complexas (JEBB, 1997), de fato, o seu desenvolvimento possui múltiplas causas e é o resultado de complexas interações entre fatores genéticos, psicológicos, socioeconômicos, culturais e ambientais (BLUMENKRANTZ, 1997).

\section{1 - Fatores Exógenos ou Primários}

\subsection{1 - Desbalanço Nutricional}

O balanço energético positivo tem extrema influência para a etiologia da obesidade exógena, a excessiva ingestão alimentar torna-se um fator de alta relevância. Os estudos sobre alimentação tornaram-se importantes a partir da "revolução alimentar" que vem ocorrendo nas últimas décadas, caracterizada pela mudança nos hábitos alimentares da sociedade, devido a alterações no estilo de vida, passou a ter menos tempo para realizar suas refeições de forma adequada e balanceada, recorrendo a fast-foods, estes, normalmente fornecem alimentos 
gordurosos e com alto valor calórico, apresentam sabor agradável dos alimentos que leva a ingestão de um volume maior de alimentos (DÂMASO, 2003).

Dentre os fatores alimentares, pode-se destacar o excesso de energia, principalmente, de lipídios, favorecendo o aumento da adiposidade (ROLLS \& SHIDE, 1992). Recentes estudos com mulheres obesas brasileiras têm apontado a alta ingestão de lipídios, muito freqüente nesta população (PEREIRA, 1998; FRANCISCHI et al., 1999). Outro aspecto alimentar ressaltado por Jebb (1997) é quanto a freqüência alimentar, já que os indivíduos que consomem maior número de pequenas refeições ao longo do dia apresentam peso relativamente menor do que aqueles que consomem número menor de grandes refeições.

As mudanças nos hábitos alimentares durante este século, têm sido marcadas pelo aumento do conteúdo de lipídios na dieta, que é geralmente tido como um contribuinte no aumento da incidência da obesidade (FLATT \& TREMBLAY, 1998). No entanto, Morris \& Zemel (1999) têm mostrado que o maior conteúdo de carboidratos na dieta, principalmente na forma simples, representa um fator de risco para o desenvolvimento da obesidade.

A obesidade está sendo associada a um estilo de vida sedentário e uma dieta rica em lipídios, esta parece permitir o superconsumo passivo de energia, devido a sua densidade energética e possivelmente sua baixa ação na saciedade (BLUNDELL \& STUBBS, 1998; FLATT \& TREMBLAY, 1998; WESTERTERPPLANTEGA et al., 1998). Estudos epidemiológicos indicam correlação entre o consumo de lipídios pela população e a obesidade (ASTRUP, 1993; FLATT, 1996; GREEN \& BLUNDELL, 1996; PRENTICE \& POPPITT, 1996; SHAN \& GARG, 1996; PROSERPI et al., 1997; COOLING \& BLUNDELL, 1998). No entanto, existem indivíduos que utilizam dietas ricas em lipídios e apresentam peso baixo 
ou normal, sugerindo que, possivelmente, o excesso de lipídios ingerido possa estar em equilíbrio com a quantidade consumida pelo organismo. Esta proteção pode ser fisiológica, com taxa metabólica ou oxidação de lipídios alterados, ou comportamental devido ao aumento na atividade física (FLATT, 1996; PROSERPI et al., 1997, COOLING \& BLUNDELL, 1998).

Existem algumas hipóteses que explicam a associação entre o alto consumo de alimentos ricos em carboidratos e a obesidade. A primeira hipótese foi em 1982, mostrando que a sacarose age provocando inicialmente hiperglicemia e depois hipoglicemia reativa com conseqüente sensação de fome, responsável pelo consumo excessivo de alimentos. Outra hipótese foi em 1985, baseada na hipótese de que o homem obeso, diabético ou não, apresentava um aumento do apetite para os alimentos ricos em carboidratos, devido a redução nos níveis de serotonina. Alguns casos de obesidade podem estar relacionados com o maior número de receptores de gosto na boca, por centímetro quadrado, comparativamente às pessoas normais (CÂNDIDO \& CAMPOS, 1996).

Existe o conceito de que o controle do apetite é dado pela saciedade, isto é, o decréscimo da fome e a supressão da ingestão que acompanha o consumo alimentar. Os adoçantes podem agir mudando a aceitabilidade dos alimentos e nos níveis de saciedade. A ação sobre a saciedade se dá por meio de sinais fisiológicos que influenciam os mecanismos de controle do apetite, agindo no balanço de carboidratos e lipídeos que são ingeridos. Supõe-se que os adoçantes possam induzir a eficiência da saciedade, por outro lado, sugere-se que a substituição dos carboidratos não oferece nenhuma vantagem especial no controle do apetite, além de se refletir na compensação alimentar, principalmente em alimentos ricos em lipídios ( BLUNDELL \& GREEN, 1996) 
Observando a grande maioria dos pacientes obesos pode-se concluir os excessos na ingestão de alimentos, podendo manifestar-se de forma consciente ou até adquirir caráter compulsivo, atingindo assim uma fome incontrolável. Em alguns pacientes observa-se uma ansiedade deglutória semelhante à ansiedade dos tabagistas ou dos alcóolicos. A ingestão inadequada pode-se manifestar pela ingestão de uma maior quantidade de alimentos ou através da ingestão esporádica e repetitiva de pequenas quantidades, distribuídas no decurso do dia, em que se assume um caráter inadvertido (HALPERN, 1999).

\subsection{2 - Inatividade Física / Sedentarismo}

Quanto à pratica de exercícios físicos, já e consenso que a medida que a sociedade se torna mais desenvolvida e mecanizada, a demanda por atividade física diminui, diminuindo o gasto energético diário (OMS, 1990; GRUNDY, 1998).

Segundo Weinsier et al., 1998, existe uma relação inversa entre atividade física e adiposidade, ou seja, quanto mais ativo fisicamente for o indivíduo, menor será sua chance de desenvolver obesidade, sendo o contrário também verdadeiro.

Segundo pesquisa realizada por Saris (1993), existe uma relação significativa e inversa entre o nível habitual de atividade física e o ganho de peso ao longo da vida. A redução do gasto energético pela diminuição de atividade física habitual, associada à rotina de vida diária e ao aumento do tempo em hábitos sedentários, como assistir televisão, trabalhar no computador, entre outros, levam as pessoas a se tornarem obesas.

A atividade física se praticada de forma aguda, aumenta a atividade nervosa simpática, potencializando sua ação lipolítica no tecido adiposo 
(BJORNTORP, 1983), especialmente na região abdominal. As células adiposas são ricas em receptores $\beta_{2}$ - adrenérgicos, o que as torna susceptíveis à ação lipolítica do exercício físico (WILMORE et al., 1999).

Segundo estudo de Barros (1999), realizado em trabalhadores da indústria em Santa Catarina, $46,4 \%$ dos trabalhadores não praticavam atividade físicas de lazer.

Em um estudo realizado por Santos e Coelho (2003), em trabalhadores da indústria em Joinville - SC, os resultados não divergiram de Barros (1999), a prevalência de trabalhadores insuficientemente ativos foram de $47,1 \%$, sendo $33,0 \%$ dos homens e $62,0 \%$ das mulheres. Neste mesmo estudo foi avaliado também a classificação de atividade física de acordo com o setor que trabalham nas empresas, foi observado que as pessoas mais ativas estão no setor de produção, enquanto que no setor administrativo, a prevalência de pessoas insuficientemente ativas é menor, foi avaliado a associação entre o nível de atividade física e a obesidade, a prevalência de pessoas insuficientemente ativas obesas é de $17,2 \%$, enquanto a prevalência de pessoas insuficientemente ativas não consideradas obesas é de 5,3\%. De acordo com esses dados, o risco relativo de um trabalhador insuficientemente ativo ser obeso é de 3,3\%, ou seja, há $229,0 \%$ mais chances de se encontrar trabalhadores insuficientemente ativos obesos do que trabalhadores insuficientemente ativos com percentual de gordura recomendado nessa população.

A conclusão de um estudo realizado por Negrão et al., (2000), mostrou que a prática de exercícios físicos regulares preserva a massa magra, evita o ganho de peso, é um benefício independente nas várias comorbidades da obesidade, como hipertensão, hiperglicemia e resistência à insulina. Desta maneira, um estilo 
de vida ativo, pode atenuar o risco de morbidades e mortalidades em indivíduos com sobepeso ou obesos.

\subsection{3 - Estresse, Depressão e Ansiedade}

Problemas psicológicos também estão associados ao ganho de peso, como por exemplo estresse, depressão e ansiedade (BARON, 1995; JEBB, 1997), influenciando principalmente o comportamento alimentar (STUNKARD \& WADDEN, 1992).

Entre os diversos tipos de estresses que acometem o indivíduo obeso podem ser mencionados (DÂMASO, 2002):

- Choques emocionais, tensão nervosa crônica;

- Inadaptação do meio social/familiar, demasiada rotina, frustrações emocionais;

- Mudança comportamental decorrente de aspectos repressivos, intimidação, superproteção;

- Traumatismos, cirurgias e doenças agudas.

\subsection{4 - Fatores Socioecônomicos}

Sobal e Stunkard (1989), após realizarem uma clássica revisão de 144 estudos que haviam sido publicados sobre a relação entre o nível sócio-econômico e a obesidade, encontraram uma forte relação inversa no grupo de mulheres de sociedades desenvolvidas, ou seja, mulheres de menor nível sócio-econômico eram significativamente menos obesas que aquelas de pior nível sócio-econômico. Entretanto, essa relação não era tão evidente nos grupos de homens e crianças 
em sociedades desenvolvidas e mostrou-se não ser consistente para esses dois grupos. Por outro lado, havia uma forte relação direta entre o nível sócioeconômico e a obesidade entre mulheres, homens e crianças em sociedades em desenvolvimento - quanto melhor o nível sócio-econômico, mais freqüente a obesidade nos três grupos. Os autores revisaram as atitudes sociais com relação à obesidade e encontraram valores congruentes com a distribuição da obesidade por nível sócio-econômico tanto em sociedades desenvolvidas quanto naquelas em desenvolvimento. De acordo com os autores, nas sociedades desenvolvidas, a restrição dietética, o aumento da atividade física, a mobilidade social e a hereditariedade podem mediar as atitudes com relação ao peso corporal entre mulheres de melhor nível sócio-econômico, o que resulta na relação inversa entre o nível sócio-econômico e o desenvolvimento da obesidade. O nível sócioeconômico influência a obesidade por meio da educação, renda e ocupação resultando em padrões comportamentais específicos que afetam a ingestão calórica, o gasto energético e a taxa metabólica.

Reddy (1998) estudou a relação entre o nível sócio-econômico e o índice de massa corporal em 1.119 pessoas de populações de diferentes níveis sócioeconômicos no sul do estado de Andhra Pradesh, Índia. Os resultados mostraram uma associação positiva entre o nível sócio-econômico e o índice de massa corporal, qualitativamente diferente da associação negativa observada nos países desenvolvidos.

Wardle, Waller e Jarvis (2002), investigaram os fatores sócio-econômicos preditivos de obesidade em mais de 15.000 homens e mulheres na Inglaterra e seus resultados eram conflitantes aos de Reddy, (1998), ou seja, a associação entre o nível sócio-econômico e o Índice de Massa Corporal era negativa, com o 
menor índice de obesidade na classe mais alta. Na Inglaterra, o risco de se desenvolver a obesidade é maior entre homens e mulheres de classes econômicas menos favorecidas e com menor grau de escolaridade. Esse achado era independente de outros efeitos do nível sócio-econômico e da idade, etnia e estado civil.

Estudos realizados na Suécia (KUSKOWSKA et al., 1993; SUNDQUIST et al., 1998), na Finlândia (RISSANEM et al., 1991; LAITINEN et al., 2001), na Suíça (GALOBARDES et al., 2000) e nos Estados Unidos (FLEGAL et al., 1988) apresentaram resultados semelhantes, ou seja, uma relação entre baixos graus de escolaridade ou nível sócio-econômico baixos e o desenvolvimento da obesidade.

Monteiro et al., (2000), compararam dados coletados em três pesquisas nas duas regiões mais populosas do Brasil em 1975 (n: 95.062), 1989 (n: 15.585) e 1997 (n: 10.680). As tendências iniciais apontavam um aumento da obesidade em todos os grupos populacionais (exceto entre os homens na área rural). Entretanto, dados mais recentes mostram um quadro mais complexo com um aumento mais acentuado da obesidade entre os homens que entre as mulheres, maior na área rural e nas famílias mais pobres. Surpreendentemente, o índice de obesidade era menor nas mulheres de grupos de nível sócio-econômico mais elevados, principalmente nas áreas urbanas. Os autores concluíram que essa tendência recente de redução significativa na prevalência da obesidade entre mulheres de nível sócio-econômico mais elevados de áreas urbanas é única em um país em desenvolvimento. Eles acreditam que essa tendência no declínio da obesidade pode ser uma conseqüência de uma intensa campanha dos meios de comunicação que combate o estilo de vida sedentário e incentiva a adoção de dietas mais saudáveis. 


\subsection{5 - Herança Genética}

De acordo com a pesquisa realizada por Gigante et al., (1997), as pessoas que referiam obesidade da mãe e do pai, apresentaram um risco de obesidade quase duas vezes maior que aqueles cujos pais não eram obesos.

A transmissão familiar da obesidade é bem conhecida segundo Locard et al., (1992), acredita-se que pode ser tanto por fatores genéticos como por estilo de vida (RAVUSSIN et al., 1992).

De acordo com Pérusse, (2002), houve um progresso na pesquisa de genes responsáveis pela obesidade. As atualizações anuais do mapa genético da obesidade, publicado desde 1996, oferecem uma boa indicação do progresso realizado nos últimos 15 anos nessa área. Estudos de biologia molecular mostram fortes evidências de que os genes poderiam estar envolvidos na determinação da obesidade humana. Esses estudos identificaram casos de obesidade humana devido a deficiências em determinados genes. Até o momento, há 78 casos de obesidade devido a mutações em um dos sete genes identificados. A maioria desses casos foi observada em indivíduos com obesidade grave, com instalação da obesidade quando ainda jovens. A pesquisa por genes relacionados ao sobrepeso e à obesidade em seres humanos baseia-se, principalmente, nos estudos de associação e/ou ligações com genes candidatos, que são aqueles metabólica ou fisiologicamente relevantes para o genótipo estudado (genes candidatos funcionais) ou com genes que se tornaram alvos primários por causa de sua posição física em uma determinada região do genoma (gene candidato posicional), geralmente descoberto por mapeamentos do genoma.2 
Os QTLs (quantitative trait locus), refere-se à posição no cromossomo ocupada por um gen particular no qual a segregação contribui para a característica quantitativa, como é o caso do IMC (Índice de Massa Corporal) para a obesidade. Os QTLs para obesidade descobertos no mapeamento genético definem as regiões cromossômicas, ou, às vezes, genes candidatos posicionais que podem ser melhor investigados para se determinar seus papéis no fenótipo de interesse. Até o momento, publicaram-se 24 estudos de mapeamento de genoma para obesidade, realizados em 14 grupos diferentes, com vários fenótipos de obesidade. Esses estudos para obesidade identificaram aproximadamente 60 QTLs de obesidade, distribuídos em todos os cromossomos, com exceção dos cromossomos 21, 22 e Y. O cromossomo 2 é o que abriga o maior número de QTLs para obesidade: cinco. Apesar do número elevado de QTLs de obesidade encontrados, poucos foram identificados em um outro grupo, que incluía QTLs no cromossomo 2p21, 3q27, 4q31-q32, 5p13.3, 10p15 e 14q11-q11.2. Esses resultados indicam claramente que a obesidade é uma doença complexa e heterogênea, influenciada por diversos genes, entretanto, a combinação dos genes envolvidos no desenvolvimento das formas mais comuns da obesidade ainda não foi determinada (Pérusse, 2002).

Evidências mais definitivas da influência dos fatores genéticos no desenvolvimento do sobrepeso e da obesidade deverão proceder de estudos envolvendo pares de gêmeos com diferentes tipos de relação genética. Os gêmeos monozigotos apresentam material genético idêntico, enquanto os heterozigotos possuem a mesma diversidade de irmãos não-gêmeos (Guedes, 2002) 
Comparando estudos que procuraram associar o índice de massa corporal entre irmãos, envolvendo pares de gêmeos monozigotos e heterozigotos que viviam juntos e em separado, constata-se que os resultados são muito mais similares e não oferecem, portanto, maior convicção quanto ao fato de o sobrepeso ser mais susceptível ao controle dos fatores genéticos (MCARDLE et al., 1990).

Em estudos de Cloninger et al., (1979), foi utilizado delineamento no tratamento das informações do tipo "path analysis"- modelo BETA - um grupo de pesquisadores procurou fornecer subsídios que talvez possam auxiliar na elucidação dos aspectos genéticos e do ambiente no sobrepeso e na obesidade. Essa técnica de análise vem sendo advogada como um dos recursos mais eficientes na tentativa de isolar os efeitos transmissíveis associados aos componentes genéticos e não genéticos ou culturais, dos efeitos não transmissíveis em fenótipos multifatoriais, como parece ser o caso da obesidade e do sobrepeso.

Quanto aos padrões de distribuição de gordura, os aspectos genéticos apresentam maior influência na época em que os hormônios andrógenos estão sendo produzidos em maiores proporções, ou seja, na adolescência (KAPLOWITZ et al., 1988).

$\mathrm{Na}$ associação entre a demanda energética voluntária/involuntária e os fatores genéticos verifica-se que o índice metabólico de repouso e o efeito térmico dos alimentos demonstram efeitos genéticos aditivos por volta de $40,0 \%$ da variação total do fenótipo (BOUCHARD et al., 1989), ao passo que o coeficiente de hereditariedade do nível de prática de atividade física habitual alcança valores próximos a 25 - 30\% (PÉRUSSE et al., 1989). Significativo efeito genético 
também foi observado no índice de trocas respiratórias em esforços submáximos, sugerindo que alguns indivíduos podem apresentar capacidade de oxidação de lipídios ou carboidratos relativamente maior que outros como resultado de diferenças herdadas (BOUCHARD et al., 1989).

Sintetizando o papel do genótipo na variação do sobrepeso e da obesidade: se as evidências têm apontado para um menor efeito genético aditivo quanto ao índice de massa corporal e às quantidades de gordura corporal, parece também que pode existir interação entre genótipo $x$ ingestão excessiva de calorias e genótipo $x$ demanda energética voluntária e involuntária. Esses conceitos oferecem indicações de que, em razão dos aspectos hereditários, alguns indivíduos podem demonstrar risco mais elevado que outros para apresentar sobrepeso ou se tornarem obesos, o que enfatiza a necessidade de controlar o aporte calórico e os níveis de prática da atividade física. Desse modo, salvo em casos patológicos, o sobrepeso e a obesidade somente poderão desenvolver-se quando existir situação ambiental favorável ao equilíbrio energético positivo e, portanto, devem ser encarados como disfunção comportamental (GUEDES \& GUEDES, 2002).

\subsection{6 - Hábitos alimentares instalados na infância}

Em crianças e adolescentes a obesidade tornou-se uma questão de saúde pública por alguns motivos, um deles é que o excesso de peso e gordura corporal em crianças e adolescentes aumenta o risco de adultos apresentarem sobrepeso ou obesidade (GUO et al., 1994), outro motivo é que o sobrepeso e a obesidade em idades precoces podem estar associados ao aparecimento e ao 
desenvolvimento de fatores de riscos que podem predispor os adultos à maior incidência de distúrbios metabólicos e funcionais (ERNST \& OBARZANEK, 1994), outro motivo relevante é que a conseqüência do sobrepeso no adulto pode resultar em comportamentos e hábitos inadequados e de difícil modificação, quanto à dieta e à atividade física, incorporados nessa fase da vida (HIMES \& DIETZ, 1994).

Estudos demonstram que $35-40 \%$ dos adultos com sobrepeso apresentavam excesso de peso corporal nos primeiros anos de vida (CHARNEY et al., 1976).

Conseqüências sociais, psicoemocionais, metabólicas e funcionais induzidas pelo excesso de gordura na infância estimulam maior ingestão de alimentos e limitam a participação das crianças em atividades físicas, favorecendo, a persistência do quadro de obesidade (GUEDES \& GUEDES, 2002).

Um estudo realizado por Guedes \& Guedes (1997), em Londrina - Paraná, em uma população escolar com amostragem estratificada aleatória, observou que a prevalência de obesidade foram similares às encontradas na população jovem americana, neste estudo foi verificado que $20,0 \%$ de meninas e $17,0 \%$ de meninos entre 13 e 17 anos foram classificados como obesos. 


\section{2 - Fatores Endógenos ou Secundários}

\subsection{1 - Doenças Endócrinas}

Desordens endócrinas podem conduzir a obesidade, como o hipotireidismo e problemas do hipotálamo, mas estas causas representam menos de 1,0\% dos casos de excesso de peso. Outros problemas dessa mesma origem incluem alterações no metabolismo de corticoesteróides, hipogonadismo em homens e ovariectomia em mulheres, e a síndrome do ovário policístico, a qual pode estar relacionada a mudanças na função ovariana ou à hipersensibilidade no eixo hipotálamo-hipófise-adrenal (BARON, 1995; JEBB, 1997).

Em pessoas obesas, as mudanças na secreção e na ação hormonal resultam dos efeitos do progressivo balanço calórico positivo e do excesso de adiposidade. Por outro lado, a função endócrina é afetada pela presença da obesidade, como, por exemplo, em relação à secreção de insulina alterada, podendo causar diabetes mellitus tipo II (HEBER, 1994).

Algumas disfunções endócrinas são responsáveis pela obesidade em indivíduos acometidos por algumas síndromes relacionadas a seguir (HALPERN, 1999; HEBER, 1994):

Síndrome de Cushing: decorrente de alterações no sistema hipofisário, glândulas adrenais e/ou decorrente de tratamentos prolongados com glicocorticóides. Caracterizada por alterações metabólicas, como aumento do catabolismo muscular, podendo desenvolver osteoporose e adelgaçamento da pele formando estrias purpúreas, além de disposição de gordura localizada na região cervical posterior. 
Obesidade tireoidiana: pode ser causada por doença tireoidiana auto-imune, radioterapia, intervenção cirúrgica do hipertireoidismo, câncer na tireóide, deficiência de iodo e defeitos congênitos.

Obesidade gonadal: inclui casos hipogenitalismo em ambos os sexos, transtornos cromossômicos (síndrome de Turner) e alterações relacionadas com hiperandrogenismo.

Síndromes hipotalâmicas: podem ser caudas por destruição do hipotálamo decorrente de traumas, infecções e cânceres, bem como por síndromes hipotalâmicas genéticas.

Pseudo-hipoparatireoidismo: decorrente de insensibilidade do túbulo renal ao paratormônio, mesmo na presença da função normal das glândulas paratireóides.

Hiperinsulinemia: está relacionada com o diabetes mellitus não-insulino dependente; contudo, nem todo paciente com essa doença é necessariamente obeso.

\subsection{2 - Drogas}

Alguns medicamentos usados no controle de outras doenças podem determinar excesso de apetite e consequentemente obesidade por ingestão alimentar (HALPERN \& MANCINI, 1996).

O uso indevido e abaixa quantidade de informações são aspectos que favorecem o surgimento da obesidade por origem medicamentosa (DÂMASO, 2002). 


\subsection{3 - Neurológicos}

Tumores hipotalâmicos e patologias tumorais hipofisárias comprometem os centros hipotalâmicos da fome e da saciedade, ocasionando a obesidade. Sintomas como cefaléia, vômitos e alterações na visão, bem como em crianças, atraso de crescimento (craniofaringiomas), essas afecções são raras (HALPERN, 1999).

\subsection{4 - Metabólicos}

Uma das causas mais freqüentes de obesidade é a redução da taxa metabólica basal (TMB) (WILMORE \& COSTILL, 2001).

Vários fatores estão relacionados à taxa metabólica basal relacionados a seguir:

Quantidade de massa magra: quanto maior for a porcentagem de massa magra de indivíduo, maior será seu gasto calórico diário. Pesquisas demonstram que a menor taxa metabólica basal das mulheres, devido a uma maior quantidade de massa gorda, pode explicar a maior adiposidade em mulheres, quando comparadas a homens (GORAN \& WEINSIER, 2000).

Temperatura corporal: quanto maior a temperatura corporal maior será a taxa metabólica basal, o que explica em parte a grande adiposidade de pessoas que habitam locais mais frios.

Depressão: diminui a atividade do sistema nervoso simpático, o que reduz a taxa metabólica basal. 
Hormônios: a tiroxina e a adrenalina atuam aumentando a taxa metabólica basal, e assim a deficiência na síntese, na secreção ou na atuação fisiológica desses hormônios pode causar o efeito inverso.

Idade: em decorrência da idade há uma pronunciada redução na quantidade de massa magra. Grundy (1998) destaca em sua revisão que o envelhecimento também está ligado ao ganho de peso, por estar associado a fatores como declínio na TMB em conseqüência da perda de massa muscular, diminuição na prática de atividades físicas e aumento no consumo alimentar.

Área corporal: quanto maior a área superficial corporal, maior perda de calor ocorrerá pela pele, o que leva a taxa metabólica basal porque é necessária uma maior perda de energia para manter a temperatura corporal. 


\section{3 - DOENÇAS RELACIONADAS A OBESIDADE}

\section{1 - Cardiovasculares}

No Brasil as três principais causas de morte são o infarto do miocárdio, o acidente vascular cerebral (AVC) e a insuficiência cardíaca, representando 300 mil mortes anuais. A doença cardiovascular no Brasil está associada a 34,0\% do total de mortes (SBC, 1999). Os países com as maiores taxas de morte por doenças cardiovasculares são a: Federação Russa $(45,2 \%)$, Bulgária $(53,6 \%)$, Inglaterra $(45,4 \%)$, Alemanha $(39,6 \%)$, Noruega (45\%), Áustria $(40,3 \%)$ e Estados Unidos (38,8\%) (KRUMMEL, 1998).

A relação entre obesidade e doença cardiovascular é melhor ilustrada nos resultados de Blumenkrantz, (1997), nos quais mostra que um aumento de $10 \%$ no peso corporal aumenta a incidência de doenças coronarianas em $20,0 \%$, com isso o coração torna-se predisposto a aumentar o rendimento cardíaco para atender as necessidades metabólicas corporais. Os mecanismos desta associação com a obesidade são variados e atuam na agressão miocárdia, ocasionando uma disfunção ventricular, podendo ocorrer também uma elevação do colesterol plasmático em torno de $12 \mathrm{mg} / \mathrm{dl}$.

A localização do tecido adiposo na região abdominal predispõe a problemas cardiovasculares. Uma forma simples de realizar a medição do grau de adiposidade intra-abdominal é na razão entre as circunferências da cintura e do quadril, nos homens esse valor é aumentado quando estiver acima de 1,0 e nas mulheres acima de 0,8. Quando ocorre em mulheres pré-menopausa, há diminuição progressiva na ligação entre os hormônios sexuais e a globulina, 
aumentando a concentração de testosterona livre, o que eleva a atividade androgênica e as concentrações de AGL. Em mulheres pós-menopausa a deficiência de estrógeno contribui para a distribuição de tecido adiposo característico do sexo masculino, e a perda da função ovariana está associada com o desenvolvimento de problemas aterogênicos (GASPARD, 1995).

Kenchaiah (2002), após realizar correção dos fatores de risco conhecidos (ajuste de variáveis), mostrou que houve um aumento no risco de falência cardíaca de 5,0\% para homens e de 7,0\% para mulheres para cada aumento de uma unidade no IMC Índice de Massa Corporal), e não é limitado apenas para a obesidade mórbida, criando um contínuo gradiente de risco de falência ventricular. O efeito da ativação do sistema nervoso simpático e da ação miocardiótóxica das catecolaminas circulantes precisa ser avaliado na gênese ou na participação da disfunção cardíaca em indivíduos obesos.

As agressões da obesidade aos níveis de pressão arterial têm sido observadas em praticamente todas as sociedades, idades, grupos étnicos e ambos os sexos. Estudos revelam que a prevalência da hipertensão em obesos é 2,9 vezes maior do que em não-obesos (VAN, 1985).

Acompanhamentos longitudinais destacam que, a cada $10,0 \%$ de aumento no peso corporal relativo, a pressão arterial sistólica responde como elevações por volta de 6,5 mmHg (KANNEL et al., 1967). Resultados de meta-análise demonstraram que na redução de $1 \mathrm{~kg}$ de peso corporal há diminuição de 1,2-1,6 $\mathrm{mmHg}$ de pressão arterial sistólica e 1,0-1,3 $\mathrm{mmHg}$ da pressão arterial diastólica (STAESSEN et al., 1989).

No desenvolvimento do diabetes mellitus o tecido adiposo atua aumentando a demanda por insulina e, em pacientes obesos, criando resistência à esta, 
ocasionando aumento na glicemia e conseqüente hiperinsulinemia. Esta sensibilidade do tecido adiposo à insulina pode permanecer alta, sugerindo que a lipogênese possa estar favorecida. Essa resistência pode ser atribuída à diminuição na concentração de receptores de insulina ou na falha no mecanismo de trânsito celular (BLUMENTRATZ, 1997).

\section{2- Respiratórios}

Uma das disfunções pulmonares nos indivíduos obesos é chamada de síndrome de Pickwickian ou síndrome da obesidade-hipoventilação, caracterizada por sonolência e redução da ventilação (KOPELMAN, 1992).

Quando há um aumento no peso corporal, ocorre a sobrecarga muscular para a ventilação, o que resulta numa disfunção da musculatura respiratória (BLUMENTRATZ, 1997). Além disso, o aumento na quantidade de gordura acumulada na região peitoral e abdominal limita os movimentos respiratórios e diminui o volume pulmonar (JUNG, 1997).

A obesidade também tem sido associada à prevalência de asma, sendo que os mecanismos pelos quais a obesidade promove essas dinfunções respiratórias tem sido atribuídos a fatores mecânicos, como o volume abdominal, sobre a expansão pulmonar e as vias aéreas superiores (SCHACHTER et al., 2001). 


\section{3- Ortopédicos}

O excesso de peso corporal predispõe o indivíduo obeso a sofrer traumas nas articulações, como é o caso da osteoartrite no joelho, o excesso de tecido adiposo pode atuar no sistema esquelético, devido à alteração no metabolismo de estrógeno (ROSSNER, 1989; BOLLET, 1992).

\section{4- Endócrinos}

Meninas obesas possuem muitas vezes a menarca mais cedo que as nãoobesas, já que a menstruação é iniciada quando o peso corporal atinge certa massa corporal crítica (BLUMENKRANTZ, 1997).

Segundo Givens, (1992), as mulheres que apresentam obesidade abdominal desenvolvem irregularidades no ciclo menstrual e amenorréias e apresentam mais problemas durante a gravidez, como a síndrome hipertensiva e a toxemia.

\section{5- Neoplasias}

Homens obesos apresentam um índice de mortalidade significante por câncer colorectal e de próstata, os que apresentam peso maior que $130 \%$ do peso médio apresenta 2,5 mais chances de morrer por câncer de próstata do que os normais. Mulheres com sobrepeso podem desenvolver câncer do colo uterino, ovário e mama (BLUMENKRANTZ, 1997). 


\section{6 - Vesícula Biliar}

A associação entre a obesidade e o cálculo da vesícula biliar, pode estar relacionado a dois fatores: aumento no colesterol circulante, quando os estoques de tecido adiposo são mobilizados, e aumento na taxa em que o colesterol é excretado na bile (JUNG, 1997).

\section{7 - Outras Disfunções}

Algumas desordens estão associadas a obesidade, segundo Baron, (1995), como: doenças do trato digestivo (fígado, esofagite), tromboembolias, diminuição na capacidade cardíaca, problemas de pele, maior incidência de complicações cirúrgicas e obstétricas, maior suscetibilidade a acidentes e maior incidência de problemas psicológicos e discriminação social. 


\section{4 - ASPECTOS PSICOLÓGICOS}

Diversos têm sido os fatores psicológicos associados à obesidade e viceversa, dentre esses fatores, merecem destaque a bulimia e a anorexia nervosa, a ansiedade, a depressão e o transtorno do comer compulsivo (TCC).

Estudos de atitudes frente à vontade de se alimentar permitiram individualizar dois desvios psicológicos associados ao comportamento alimentar: anorexia e bulimia. A anorexia nervosa caracteriza-se pelo desejo persistente de manter o peso corporal abaixo dos limites inferiores aceitáveis, devido muitas vezes a preocupação com a imagem corporal. A bulimia caracteriza-se por episódios repetidos à impulsão irresistível de ingestão de grandes quantidades de alimentos em curtos espaços de tempo, durante os quais se perde a noção d quanto se come e a capacidade de parar. Nos casos em que a obesidade não é desejada, as crises bulímicas são compensadas pelo abuso de laxantes, diuréticos e anorexígenos, bem como pela provocação do vômito, enquanto as anoréxicas o são pelo recurso do jejum (FOSTER, 1992).

A obesidade não é classificada como um transtorno psiquiátrico, por muito tempo foi compreendida como uma manifestação somática, uma conseqüência de um conflito psicológico subjacente que o indivíduo obeso só conseguiria resolver por meio da hiperfagia, atualmente esta não é uma postura aceita, estudos sugerem que não há diferenças significativas no funcionamento psicológico entre pessoas obesas e não obesas (HALPERN \& MANCINI, 2002).

Nos pacientes obesos que procuram tratamento, existe um aumento de prevalência de sintomas psicológicos, tais como depressão, ansiedade e aumento 
da ingestão alimentar, pacientes com co-morbidades psiquiátricas apresentam maiores taxas de abandono no tratamento (HALPERN \& MANCINI, 2002).

O estigma da obesidade se caracteriza por uma diversidade de atitudes negativas frente aos obesos, como, menor chance de um relacionamento afetivo, menor chance de se empregar, objetos de uso diário com ergonomia inadequada; uma mudança comportamental é o aspecto inicial para resolução desses problemas (HALPERN \& MANCINI, 2002).

Sentimentos de perda e depressão explicam o modo como certos indivíduos procuram insistentemente e repetidamente alimentos açucarados. Os açucares são necessários para a produção de opióides, principalmente betaencefalinas e dimorfinas, substâncias com várias funções que, no cérebro, provocam sensação de bem-estar. Isso explica como os alimentos doces atuam em alguns indivíduos como reguladores de tensões (WADDEN \& STUNKARD, 1985).

A Psicoterapia Cognitivo-Comportamental (PCC) tem como base a análise funcional dos comportamentos, qualquer que seja sua indicação, isto é, transtornos psiquiátricos propriamente ditos ou obesidade, sendo que no caso da obesidade, a PCC objetivará o clareamento da associação entre o binômio ingestão alimentar-atividade física numa ponta e eventos ambientais, tais como horários, presença de outras pessoas e humor, na outra, para que, por meio disso, a mudança desejada seja implementada (HALPERN \& MANCINI, 2002).

Outro aspecto psicológico relevante nos pacientes obesos é o Transtorno do Comer Compulsivo (TCC), caracterizado por episódios repetidos de comer compulsivamente, com uma freqüência de no mínimo duas vezes por semana durante seis meses consecutivos. Este transtorno está presente em 5,0 a 8,0\% da 
população obesa geral e em 20,0 a 30,0\% dos obesos mórbidos que procuram tratamento, sendo mais freqüente entre as mulheres (HALPERN \& MANCINI, 2002).

O diagnóstico da psicogênese da obesidade é estabelecido por meio da realização de uma anamnese, em que mostra que o paciente apresenta modificações do comportamento alimentar, como "síndrome da ingestão noturna" ou "síndrome da compulsão alimentar", estas síndromes estão associadas a uma fase de estresse psicológico, distúrbio e ansiedade crônica (HALPERN, 1999).

As doenças do comportamento alimentar obedecem a uma interação entre distúrbio fisiológico e distúrbio psicológico. Nestes casos, o alimento passa a ser um substituto de outras gratificações ou pode ser utilizado para alívio da solidão, da ansiedade ou dos aborrecimentos. A superalimentação pode funcionar como um mecanismo para afastar sentimento desconfortantes de agressividade ou depressão, sendo que a obesidade pode ser utilizada como mecanismo de defesa contra a interação social anormal, conflitos sexuais e exposição à possibilidade de inter-relações pessoais inadequadas (HALPERN, 1999). 


\section{5 - TRATAMENTO DA OBESIDADE}

A adequada quantidade de massa corporal, em especial de gordura, melhora a qualidade de vida contribui para a diminuição da morbi-mortalidade. Segundo um estudo realizado por Jung, (1997), foi observado que a redução do peso corporal em $10 \mathrm{~kg}$ apresenta os seguintes benefícios:

Mortalidade: ocorre uma queda de 20,0 - 25,0\% na mortalidade total; há um declínio de 30,0 - 40,0\% nas mortes por diabetes melittus; há uma redução de $40,0-50,0 \%$ nas mortes por neoplasias da obesidade.

Pressão arterial: queda de $10,0 \mathrm{mmHg}$ na pressão sistólica e $20,0 \mathrm{mmHg}$ na distólica.

Angina: redução dos sintomas em $91,0 \%$; aumento de $33,0 \%$ na tolerância ao exercício.

Lipídios: diminuição de 10,0\% no colesterol total; declínio de 15,0\% no LDLcolesterol; diminuição de 30,0\% nos triglicérides circulantes; aumento em 8,0\% no HDL-colesterol;

Diabetes: redução no risco de desenvolvimento de diabetes maior que do que 50,0\%; diminuição de 30,0 - 50,0\% na glicemia de jejum.

\section{1 - Tratamento Dietoterápico}

As intervenções dietéticas nos programas de controle do peso corporal requerem elaboração de planos de dietas que venham a oferecer diminuição no consumo calórico total, com isso, o organismo passa a receber menor aporte calórico do que precisa; em conseqüência, vai buscar as demais calorias 
necessárias em seus depósitos energéticos, tanto mais quanto maior for o dispêndio de energia requerido para atendimento às solicitações biológicas (KRAMER et al., 1989).

Segundo recomendação da ACSM, (1983) a perda de peso deve ser resultado da máxima redução de gordura corporal e de mínima perda de massa magra, representando sucesso na manutenção do peso perdido, poucos riscos de desnutrição e de complicações médicas.

O total energético deve ser controlado para pacientes que apresentam síndrome metabólica, afirmando que a dieta deve conter alta porcentagem de energia derivada de carboidratos e baixa de lipídios, além de controle na quantidade de colesterol na dieta, a fim de reduzir as chances de ocorrência de problemas cardiovasculares (ILARDE \& TUCK, 1994). Lean et al., (1989), defendem dietas ricas em carboidratos e pobre em lipídeos, para prevenção da obesidade e manutenção do peso adequado. De fato, a composição da dieta parece influenciar a redução de peso: dietas ricas em lipídeos podem criar balanço positivo deste nutriente no organismo, ou seja, seu consumo é maior do que a sua oxidação. Isso ocorre porque o aumento na ingestão de lipídeos não estimula a sua oxidação, o que ocorre em carboidratos e proteínas, e porque a eficiência do organismo em estocar os lipídeos da dieta como reservas de gordura é muito alta, superior a 95,0\% (HILL et al., 1993).

A importância das fibras na alimentação para redução da obesidade, consiste na redução na ingestão energética; aumento no tempo de esvaziamento gástrico; diminuição na secreção de insulina; aumento na sensação de saciedade; redução na digestibilidade; redução no gasto energético e aumento na excreção fecal de energia (ROSSNER, 1992). 


\section{2- Exercícios Físicos}

O exercício físico regular resulta em benefícios para o organismo, melhora a capacidade cardiovascular e respiratória, diminui a pressão arterial dos hipertensos, melhora a tolerância à glicose atuando na ação da insulina (DENGEL et al., 1998).

O exercício físico é uma forma relativamente eficaz no tratamento da obesidade, pois eleva o gasto energético e minimiza os efeitos negativos da restrição energética, pois é capaz de reverter a queda na TMB (MOLÉ et al., 1989). Segundo Forbes (1992), o exercício aeróbio preserva a massa magra, e ajuda a manter a TMB durante um programa de redução de peso, desde que não haja um déficit energético muito grande. Além disso, a combinação da dieta e de exercícios de intensidade moderada geralmente promove uma maior perda de peso do que a dieta isolada. O exercício combinado à restrição energética promove a redução no peso corporal, maximizando a perda de gordura e minimizando a perda de massa magra (RACETTE et al., 1995).

\section{3- Medicamentoso}

O tratamento medicamentoso para a redução da obesidade utiliza algumas drogas como: anfetaminas, fenfluraminas, fenterminas, dietilpropina, manzindol, pemolina, fenilpropanolamina e os anti-depressivos, fluoxitena e sertralina, entre outros. Há muitas controvérsias sobre a utilização destes, pelos escassos estudos sobre seus efeitos a longo prazo. Os remédios criam uma expectativa de cura para a obesidade e as pessoas comumente voltam a engordar com a suspensão 
do medicamento. Os efeitos colaterais normalmente observados incluem sonolência, nervosismo e distúrbios no trato gastrointestinal (BARON, 1995).

\section{4- Promoção da obesidade}

A importância da redução da obesidade para a saúde pública, o interesse social e os investimentos econômicos em alimentação e na qualidade de vida de pessoas obesas indicam que, estudos rigorosos sobre a prevenção e o tratamento da obesidade são fundamentais (HYMAN et al., 1993).

Freitas (2001), relata que a prevenção da sobrecarga ponderal ou a reversão de pequenos ganhos de peso, torna-se, menos dispendiosa e mais eficaz do que tratar a obesidade depois de completamente instalada.

Freitas (2001), cita 3 níveis de ação de prevenção:

\section{1ํnível - Ações ou medidas de Saúde Pública}

Estratégias de intervenção em saúde pública são usadas para dominar a obesidade, dentre elas podemos citar duas medidas eficazes:

- Melhorar os conhecimentos e capacidade de lidar com os problemas dos indivíduos da comunidade através de estratégias de educação e alteração do comportamento, alargadas a uma grande audiência através dos meios de comunicação social, intervenções nos locais de trabalho, programas escolares, centros comunitários e clubes, entre outros. 
- Reduzir a exposição da população a ambiente promotor de obesidade, como a tentação dos alimentos de elevado conteúdo de gordura e evitar um estilo de vida sedentário. Isto é conseguido pela promoção de padrões de alimentação saudável e atividade física, envolvendo todos os níveis de política de saúde, incluindo educação, transportes, outros serviços públicos, agricultura e produção alimentar.

A autora cita estratégias ambientais para o controle da obesidade:

- Desenho urbano e política de transportes:

Construção de passeios e pistas de bicicletas seguras;

Melhoria da iluminação para marcha segura;

Tráfego calmo para melhor segurança das crianças;

Melhoria do design das construções para incentivar o uso de escadas.

- Regulamentação e legislação:

Implementação da etiquetagem dos produtos alimentares;

Limites de publicidade para crianças;

Regulamentação que assegure que os vegetais e saladas sejam servidos sem custos em todas as refeições.

- Incentivos econômicos:

Subsídios para produtos de alimentos com baixo conteúdo energético (frutas e vegetais);

Diminuição de impostos para utilizadores de transportes públicos para o trabalho; Diminuição de impostos para empresas que proporcionam exercício ou facilidades de horários aos funcionários.

Melhoria dos padrões de distribuição e preparação de comida 
Padronização nutricional das refeições nas escolas e locais de trabalho.

- Educação e promoção:

Conhecimentos da comunidade sobre obesidade;

Alterações de comportamento e estilos de vida saudável;

Necessidade de uma ação coletiva para melhorar o ambiente, promover o exercício e hábitos saudáveis.

\section{2o nível - Prevenção seletiva}

Os programas de prevenção seletiva têm como alvo os sub-grupos da população, que têm elevado risco individual de desenvolver obesidade. Estes subgrupos têm fatores biológicos, psicológicos e sócio-culturais que estão associados a risco aumentado de obesidade. Este risco pode ser agudo, como em certas fases vulneráveis da vida (adulto jovem após o casamento, gravidez, menopausa, após deixar de fumar) ou pode ser permanente como a predisposição genética para o ganho de peso.

\section{3ำ nível - Prevenção específica}

A prevenção específica é dirigida a um determinado grupo alvo, são indivíduos de alto risco, com sobrecarga ponderal, mas ainda não obesos. Os programas de prevenção específica normalmente envolvem estratégias de trabalho com os doentes numa base individual ou, alternativamente, em grupos especiais.

Os doentes recrutados para estes programas de prevenção específica já têm alguns problemas relacionados com o peso. Os objetivos primários desta estratégia de prevenção serão citados a seguir: 
- Impedir que crianças com sobrecarga ponderal se tornem adultos obesos;

- Prevenir maior ganho de peso;

- Reduzir o número de indivíduos que desenvolvem comorbilidades relacionadas com a obesidade. 


\section{Conclusão}

Frente ao exposto foi possível observar que a obesidade tem se tornado um problema crescente de saúde pública, com repercussões geográficas quase indiscriminadas afetando países desenvolvidos e em desenvolvimento, apresentam etiologia, associações multifatoriais com distribuição em todas as faixas etárias como predomínio nas faixas mais elevadas e no sexo feminino.

Foi observado que vários fatores contribuem para o desenvolvimento da obesidade, como predisposição genética, estilo de vida, fatores sócio-culturais e étnicos. Além disso, os maus hábitos alimentares e a falta de exercício também são responsáveis pelo crescimento acelerado dessa doença.

A prevenção é o principal meio de combater a obesidade.

A atividade física é considerada uma das profilaxias, porém mais da metade da população adulta é sedentária ou inativa e isso tem atingido também as crianças. O sedentarismo é responsável por cerca de um terço das mortes por doença coronariana, câncer de cólon e diabetes.

A prática de exercícios deve ser incentivada desde a infância, criar o hábito e o interesse por uma vida ativa pode trazer benefícios do ponto de vista educacional, social além de proporcionar uma prevenção, não somente da obesidade, mas de várias doenças.

O mais importante é não deixar que se atinja a obesidade e para isso é preciso "educar".

A prevenção é o principal meio de combater a obesidade. 


\section{REFERÊNCIAS}

- ASTRUP, A. Dietary composition, Substrate balances and body fat in subjects with a predisposition to obesity. International Journal of Obesity, London, v. 17, p. 325 - 365, 1993. Supplement 3 (Discussion $415-425$ ).

- BARON, R. Understanding obesity and weight loss [on line]. 1995. [citado em 28/08/1997]. Available from www:< URL:http://www-med.stanford.edu;school; DGIM;teaching;+modules;obesity.html>.

- BARROS, M. V. G. Atividades físicas no lazer e outros comportamentos relacionados à saúde dos trabalhadores de indústria no estado de Santa Catarina. Dissertação de mestrado UFSC. Florianópolis, 1999.

- BJORNTORP, P. Physiological and clinical aspects of exercise in obese persons. Exerc. sport Sci. Rev. 1983; 11: 159-80.

- BLUMENKRANTZ, M. Obesity: the world's metabolic disorder [on line]. Beverly Hills, 1997. [citado em 28/08/1997]. Available from www:<URL:http: //www.quantumhcp.com.obesity.htm>.

- BLUNDELL, J. E.; GREEN, S. M. Effects of sucrose and sweeteners on appetite and energy intake. International Journal of obesity, v. 20, n. 2, p. 12S17S, 1996. Supplementt.

- BLUNDELL, J. E.; STUBBS, R. J. Diet composition and control of food intake in humans. In: BRAY, G. A.; BOUCHARD, C.; JAMES, W. P.T. handbook of obesity. New York. Marcel Dekker, 1998. p. 243 - 272.

- BOUCHARD, C.; DEPRES, J. P. Variation in fat distribuition with age and health implications. In: American Academy of Physical Education. Physical Activity and Aging. Champaingn, Illinois, Human Publishers, p. 78-105, 1989. 
- BRAY, G. A. Obesidad. In: International Life Science Institute. Present Knowledge in Nutrition. Sixth edition. Ilsi. North America. 1990.

- BRAY, G. A., The obese Patient. Major problems in Internal Medicine. Philadelphia. W. B. Saunders. 1976.

- CÃNDIDO, L. M. B.; CAMPOS, A. M. Alimentos para fins especiais dietéticos. São Paulo, ed. Varela, p. 423, 1996

- CHARNEY, E. et al., Childhood antecedents of adults obesity: do chubby infants become obese adults? New England Journal of Medicine, v. 295, p. 6-9, 1976.

- CLONINGER, C. R.; RICE, J.; REICH, T. Multifactorial inheritance with cultural transmission and assortative mating. III - Family structure and the analysis of separation experiments. American Journal Of Human Generic, v. 31, p. 366388, 1979.

- COOLING, J.; BLUNDELL, J. Differences in energy expenditure and substrate oxidation between high fat and fat consumers (phenotypes). International Journal of Obesity, London, v.22, n. 7, p. 612-618, 1998.

- DÂMASO, A. Obesidade, 1ํㅡㄹ. ed., Ed., Medsi, Rio de Janeiro, 2003.

- DYER, R, G. Traditional treatment of obesity: does it work? Baillieres clinical endocrinology and metabolism, London, v. 8, n. 3, p. 661 - 668, 1994.

- ERNST, N. D.; OBARZANEK, E. child health and nutrition: obesity and high blood cholesterol. Preventive Medicine, v. 23, p. 427-436, 1994.

- FLATT, J. P. Glycogen levels and obesity. International Journal of obesity, London, v. 20, n. 2, p. 1s - 11s, 1996. Supplement 2. 
- FLATT, J. P.; TREMBLAY, A. Energy expenditure and substrate oxidation. In: BRAY, G. A.; BOUCHARD, C.; JAMES, W. P.T. handbook of obesity. New York. Marcel Dekker, 1998. p. $513-537$.

- FLEGAL, K. M.; HARLAN, W. R.; LANDIS, J. R. Secular trends in body mass index and skinfold thickness with socioeconomic factors in young women. Am J. Clin. Nutr. 48. P. 535-543, 1998.

- FREITAS, P. Obesidade. [on line]. [citado em 04/06/2001]. Available from www:<URL:http://www.saudenainternet.pt/guia/index.php?file=guiaartigo\&cod= 51.html>.

- FUNDAÇÃO IBGE. Censo demográfico: resultados do universo relativos às características da população e dos domicílios - Rio Grande do Sul. Rio de Janeiro, 1989, t.1, n. 20, p. 1-668.

- Gigante, D. P.; BARROS, F. C.; POST, C. L. A.; OLINTO, M. T. A. Prevalência de obesidade em adultos e seus fatores de risco. Revista de Saúde Pública, v. 31, n. 3, São Paulo, 1997.

- GLOBARDES, B.; MARABIA. A.; BERNSTEIN, M. S. The differential effect of education and ocupation on body mass and overweight in a sample of working people of the general population. Annals Epidemiology 10, p. 532-537, 2000.

- GREEN, S. M.; BLUNDELL, J. E. Effect of fat and sucrose containing foods on the size of eating episodes and energy intake in lean dietary restrained and unrestrained females: potential for causing over consumption. European Journal of Clinical Nutrition, London, v. 50, n. 9, p. 625 - 635, 1996. 
- GRUNDY, S. M. Multifactorial causation of obesity: implications for prevention. American Journal of clinical Nutrition, Bethesda, v. 67, n. 3, p. 563S-572S, 1998. Supplement.

- GUEDES, D. P.; GUEDES, J. E. R. P. Controle do peso corporal, $2^{a}$ ed., Ed. Shape, Rio de Janeiro, 2003.

- GUEDES, D. P.; GUEDES, J. E. R. P. Exercício físico na promoção da saúde. Ed. Midiograf. Londrina, 1995.

- GUO, S.S. et al., The predictive value of childhood body mass index values for overweight at age 35 y. American Journal of Clinical Nutrition, v. 59, p. 810819, 1994.

- HALPERN, A. \& MANCINI, M. C. Obesidade: como diagnosticar e tratar. Revista Brasileira de Medicina, 53: 77-85, 1996.

- HALPERN, A. Referências importantes sobre comorbidades em obesidade (Atualização Médica, RISCO). Curso de reciclagem médica em obesidade. Fascículo 1, Ed. Americana de Publicações, São Paulo, 1999.

- HEBER, D. The Endocrinology of Obesity. In: BLACKBURN, G. L.; KANDERS, B. S. Obesity pathophysiology and treatment. Chapman \& Hall, USA, 1994.

- HILL, J. O.; DOUGLAS, H.; PETERS, J. C. Obesity treatment: can diet composition play a role? Annal of Internal Medicine, Philadelphia, v. 119, n. 7, p. 694-697, 1993.

- HIMES, J. DIETZ, W. Guidelines for overweight in adolescent preventive services: recommendations from na expert committe. American Journal of Clinical Nutrition, v. 59, p. 307-316, 1994.

- HIRSCH, J. Adipose cellularity in relation to human obesity. Advances in Internal Medicine, v. 17, p. 289 - 300, 1971. 
- JEBB, S. A. A etiology of obesity. British MedicalBulletin, London, v. 53, n. 2, p. $264-285,1997$.

- KAPLOWITZ, H. J. et al., Serial and parent-child changes in components of body fat distribuition and fatness in children from the London Longitudional Growth Study, ages two to eighteen years. Human Biology, v. 60, p. 739-758, 1988.

- KUSKOWSKA-WOLK, A.; BERGSTROM, R. Trnds in body mass index and prevalence of obesity in Swedish women 1980-90. J. Epidemiol. Community Health 47, p. 195-199, 1993.

- LAITINEN, J.; POWER, C.; JARVELIN, M. R. Family social class, maternal body mass index, childhood body mass index, and age at menarche as predictors of adult obesity. Am j. Clin. Nutr, 74, p. 287-294, 2001.

- MANCINI, M. C.; HALPERN, A. Manual de Obesidade para o Clínico, volume 1, Ed. Roca, São Paulo, 2002.

- MCARDLE, W. D.; KATCH, F. I.; KATCH, V. L. Essentials of Exercise Psysiology. Phyladelphia: Lea \& Febiger, 1994.

- MONTEIRO, C. A.; BENICIO, M. H.; CONDE, W.L.; POPKIN, B. M. Shifting obesity trends in Brazil. Euro. J. Clin. Nutr. 54, p. 342-346, 2000.

- MORRIS, K. L.; ZEMEL, M. B. Glycemic index, cardiovascular disease and obesity: Nutrition Review, New York, v. 57, n. 9, pt. 1, p. 273 - 276, 1999.

- NEGRÃO, C. E.; TROMBETTA, I. C; TINUCCI, T.; FORJAZ, C. L. M. O papel do sedentarismo na obesidade. Rev. Bras. Hipertens, vol. 7, n. 2, p. 149-155, 2000.

- PEREIRA, L. O.; FRANCISCHI, R. P.; KLOPfER, M.; PERROTI, A. C.; CAMPOS, P. L..; SAWADA, L. A.; COSTA, S. R.; LANCHA, A. H. Different 
intensities of physical activities with or without hipocaloric diet: effects on body composition, food comsumption and plasmatic profile in obese women. Medicine and Science in Sports and exercise, Baltimore, v. 30, n. 5, p. 2385, 1998. Supplement.

- PERUSSE, L. et al., Genetic and environmental influences on level of habitual physical activity and exercise participation. American Journal of Epidemiology, v. 129, p. 1012-1022, 1989.

- PERUSSE, L.; CHAGNON, Y. C.; WEISNAGEL, S. J.; RANKINEN, T.; SNYDER, E.; SANDS, J. et al. The human obesity gene map: the 2000 update. Obes. Res. p. 135-69, 2001.

- PRENTICE, A. M.; POPPITT, S. D. Importance of energy density and macronutrients in the regulation of energy intake. International Journal of Obesity, London, v. 20, n. 2, p. 18S-235S, 1996.

- PROSERPI, C.; SPARTI, A.; SCHUTZ, Y.; VETTA, D.; MILON, H.; JÉQUIER, E. Ad libitum intake of a high-carbohydrats or high-fat diet in yong men: effects on nutrient balances. American Journal of Clinical Nutrition, Bethesda, v. 66, n. 3, p. 539-545, 1997.

- REDDY, B. N. Body mass index and its associstion with socioeconomic and behavioral variables among socio-economically hetyerogeneous populations of Andhra Pradesh, India. Human Biology, 70: 901-917, 1998.

- RISSANEN, A. M; HELIOVAARA, M; KNEKP, P; REUNANEN, A.; AROMAA, A. Determinents $f$ weight gain and overweight in adult Finns. Eur. J. Clin. Nutr. 45, p. 419-430, 1991.

- ROLLS, B. J.; SHIDE, D. J. The influence of dietary fat on food intake and body weight. Nutrition Reviews, Washington DC, v. 50, n. 10, p. 283-290, 1992. 
- SANTOS, J. F. S.; COELHO, C. W. Atividade física e obesidade em trabalhadores da indústria. Revista Digital, ano 9, n. 67, 2003.

- SARIS, W. H. M. Long-term results of the tratament of obesity. Journal of Drugs Research, v.8, p. 2075-2080, 1983.

- SHAN, M.; GARG, A. High-fat and high-carbohydrate diets and energy balance. Diabetes Care, New York, v. 19, n. 10, p. 1142-1152, 1996.

- SOBAL, J. STUNKARD, A. J. socioeconomic status and obesity: a review of the Literature. Psych. 105: 206-75, 1989.

- STUNKARD, A. J. et al. The body mass index of twins who have been reared apart. New England Journal of Medicine, v. 322, p. 1483-1487, 1990.

- STUNKARD, A. J.; WADDEN, T. A. Psychological aspects of human obesity. In: BJORNTORP, P., BRODOFF, B. N. Obesity. Philadelphia: J. B. Lippincott, 1992, p. 352-360.

- SUNDQUIST, J.; JOHANSSON, S. E. The influence of socioeconomic status, ethnicity and lifestyle on body mass index ina longitudinal study. International J. Epidemiology 27, p. 57-63, 1998.

- WARDLE, J.; WALLER, J.; JARVIS, M. J. Sex diferences in the association of socioeconomic status whith obesity. Am J Public Health 92, p. 1299-1304, 2002.

- WEINSIER, R. L.; HUNTER, G. R.; HEINI, A.F.; GORAN, M. I.; SELL, S. M. The Etiology of Obesity: Contribuition of Metabolic Factors, Diet, and Physical Activity. American Journal of Medicine, 105: 145-50, 1998.

- WESTERTERP-PLANTEGA, M. S.; WIJCKMANS-DUIJSENS, N. E. G., VERBOEKET-VAN DE VENNE, W. P. G.; GRAAF, K. H., WESTSTRATE, J. A. Energy intake and body weight effects os six months reduced or full fat diets, as 
a function of dietary restraint. International Journal of Obesity, London, v. 22, n. 1, p. $14-22,1998$.

- WILMORE, J. H.; DESPRES, J. P.; STANFORTH P. R., et al., Alterations in body weight and composition consequent to 20 wk of endunrance training: the HERITAGE family study. Am J Nutr, 1999; 70: 346-52.

- WORLD HEALTH ORGANIZATION. Diet, nutrition and the prevention of chronic diseases. Geneva, 1990. p. 69 - 73. (Technical Report Series, 797). 